\title{
Bridging the Gap: Improving Students' Learning Experience through Shifting Pedagogical Practices In Higher Education
}

\author{
Jennifer Rowley \\ Sydney Conservatorium of Music, The University of Sydney \\ Building C41, Sydney NSW 2006 Australia \\ Tel: +61-2-9351-1328 E-mail: Jennifer.rowley@sydney.edu.au
}

Doi:10.5296/ijld.v4i1.4944ＵRL: http://dx.doi.org/10.5296/ijld.v4i1.4944

\begin{abstract}
Curriculum modelling is a necessary pedagogical practice for teachers in higher education and appropriately designed curricula has the potential to reinvigorate student learning. Learning goals established collaboratively and sequentially across different courses in a program's curriculum contribute to an assurance of learning (AOL) and involve students in quality teaching and learning experiences. If learners respond to explicit teaching how do we prepare students for the demands of professional practice? This paper describes the process of curriculum modelling that relies on the matching of professional standards (set by industry accreditation bodies) with University graduate attributes (set by the institution). In traditional curriculum design these two non-negotiable aspects are aligned with individual course outcomes, learning and teaching activities and assessment. It is proposed that embedding eLearning across curricula will ensure students engage appropriately with technology. One example is embedding reflection tasks into assessment and using an ePortfolio to document a student's learning journey.
\end{abstract}

Keywords: quality teaching, reflective practice, curriculum modelling, eLearning, professional standards, graduate attributes, student centred learning.

\section{A culture change is needed to improve quality teaching at tertiary level}

Higher education teachers who demonstrate a commitment to curriculum modelling can offer leadership to those who have relied solely on their past experiences of learning (and teaching) to guide their own teaching. The pedagogical needs of tertiary students have changed and the accountabilities of tertiary institutions to industry accreditation bodies (with their various required reporting practices) have shifted. As a result, the need for curriculum renewal has been brought to the forefront of the quality learning and teaching debate. The tertiary sector has for some time encouraged an Assurance of Learning (AOL) through the development of graduate attributes across all disciplines and more recently teachers are encouraged to focus on research enhanced learning and teaching (ReLT) and community engaged learning and teaching (CeLT). 'Winning' students and maintaining reputations in an ever-changing education 'market' is yet another new era for tertiary institutions (Rowley, 2006).

The challenge, therefore, is how to ensure best practice of the tertiary educators to engage in meaningful curriculum modelling and effective pedagogic practices (including the embedding 
of eLearning into curricula through $21^{\text {st }}$ century pedagogy) to ensure quality student learning outcomes. This paper examines the impact of:

1. The culture change required for effective quality teaching and the practice of good pedagogy. Some of the pedagogy is old wine in a new bottle but there are some new teaching approaches required to meet the needs of the 'Gen Y' and the emerging 'Gen A'. Students' use of the curriculum can be a resource in the curriculum renewal and development process by utilising the cycle of effective learning (design, test, evaluate, redesign, retest) to analyse the learning needs of students (Knowles, 1984). It's not about inventing a set of new practices but changing the culture to use new pedagogies determined as effective quality teaching in higher education.

2. Assurance of learning (AOL) is assessed and measured through the success of curricula to be appropriately aligned to meet all necessary components. To assure learning, curriculum modelling must include the alignment of professional standards (PS), learning outcomes (LO) and graduate attributes (GA) with assessment through the careful design of learning and teaching activities. This alignment allows students to achieve the set LO by practising the skills required in the PS and to develop competency in the GA. Asking students 'how do you learn?', 'how do you prefer to learn?' and 'what hinders/ helps your learning?' is necessary in designing effective curricula.

3. The necessary skills needed by teachers to match all elements essential to curriculum modelling require professional development of staff so they can create curricula that lead to a capstone experience. The capstone experience - sometimes represented by a penultimate course - allows students to demonstrate the achievement of PS and GA. An example of assisting staff in the professional development of these skills is to implement a learning partnership with a novice and an expert in curriculum renewal through the traditional mentoring model -and/or tertiary institutions design and implement quality, on going professional development training accessible to all staff.

4. eLearning - more specifically blended learning - is supplementary to face-to-face (F2F) as a pedagogy for the 21 st century learner. However, teachers need to come to the technology with the curriculum, as eLearning is a set of practices and pedagogical values that requires a curriculum reason for its implementation. Further to this the student must see teachers actually use and model the use of technology so that students will trust and engage in eLearning. This requires a commitment to professional development for teachers and support mechanisms to maintain skills and knowledge of eLearning processes as they emerge.

5. Reflection by students on their learning journey through the tertiary program can be facilitated by peers and teachers as they dialogue about the learning experience. Through reflection we see curriculum as lived, delivered and experienced and the students' professional role identity is enhanced through the activities associated with reflection (Yancey \& Wiser, 1997). Betham and Sharpe (2007) say the dialogue is also about getting the learners to match the theory with the practice. This is often termed a learning 'autobiography' which is not just telling the story but it's sharing the story and mentoring others as they read the story (Hughes, 2011). This critical account of the students' lived experience through documenting their learning journey brings together theory and practice. Reflection is not a new tool but the use of collaborative reflection is a shift for teachers in higher education because teachers have to think through the students' dialogue as they collect, select and reflect. Tertiary teachers should consider how students' dialogue contributes to their own professional development as 'reflection-in-action' and 'reflection-on-action' is an on going process that can continue through both sets of learners' professional practice as reflection 'in' and 'on' their 'knowledge' (Schon, 1987). 
6. Graduate employability is a priority for tertiary institutions and this is why the capstone experience is often prioritised in learning and teaching strategic plans. Employers want evidence of the capstone experience and an ePortfolio (electronic portfolio) provides an organised collection of evidence of the students' tertiary learning journey (Rowley \& Dunbar-Hall, 2010). The ePortfolio allows students to select what they want to showcase depending on who the reader is and how the evidence can effectively tell their story. So, in a sense, ePortfolios can be the product of a set of practices students learn through the tertiary teachers' careful curriculum planning. The capstone experience should also expect students to demonstrate their developed higher order thinking skills to evaluate what it means to become a practicing professional in their chosen field. This capstone experience is an AOL and defends the inclusion of graduate attributes being embedded into curricula throughout the whole tertiary program.

\section{Culture shift (or old wine in a new bottle)}

Known pedagogic understandings of teaching at tertiary level should be unpacked to engage teachers in an exploration of new issues relevant to effective learning and teaching for current students. Practices such as embedding eLearning into assessment through a blended learning approach; curriculum mapping at the course level and modeling at the program level with an increased understanding of how the 'Gen Y' student in tertiary education best learn will assist in re-invigorating student learning. The simple truth is that there is not just 'one' way to teach but there are 'many' identified pedagogic practices that teachers in higher education should develop competency in to ensure the achievement of the agreed student learning outcomes. The key is in identifying methods to improve tertiary teacher's practice and allowing them to practice strategies that encourage student learning and impact on their experience. For example, through the curriculum renewal process, eLearning can be embedded into curricula and can include activities that use reflective practice by both student and teacher. In this example, eLearning needs to be modelled and actively used by the tertiary teacher to make the learning and teaching experience for the student as authentic as possible. There is no argument that carefully planned professional development for the teacher is vital so they can develop skills to allow them to model such practices.

There are many myths about eLearning in higher education that place barriers to the plethora of research supporting that quality student learning can be addressed through the exploration and understanding of effective teaching strategies, reflective practice and the careful planning of curricula.

"It suits many lecturers to believe that because learning is ultimately the student's responsibility, effective teaching is an indeterminate phenomenon" (Ramsden, 2003, p. 85).

How do we challenge the strong belief among tertiary teachers that teaching in higher education is meant to be poor? It is not labelled 'poor' teaching but rather 'good' teaching because the teachers teach the way they were taught at university and, if they survived, why should it be any different for the students they have responsibility for? The culture shift that is needed should actually challenge the existing culture of teaching in higher education to better meet the $21^{\text {st }}$ century learners' needs. A revolution needs to occur where teachers unpack all they know and re learn the basics of the pedagogic process. Harvey \& Kamvounias (2008) argued the theory of student centered learning and state that tertiary teachers need to become learners. They used an argument of alignment to encourage program co-coordinators to collaborate with colleagues in their understanding of pedagogic practices. 


\subsection{AOL, professional standards and quality teaching}

The introduction of professional standards by industry and graduate standards by the tertiary institution (in their quest for quality assurance) is fraught with the potential for tertiary teachers to compromise quality teaching practices. It is an issue that demands a rigorous debate amongst those engaged in developing curricula. If the tertiary teacher charged with educating our future professionals is accountable to an accrediting body then is it more likely that quality assurance is achieved? Many professional bodies are now in the practice of accrediting the tertiary programs to ensure that very thing.

"New accountability measures, mandated professional standards and proposals to test all graduates before registration means that. ...programs need capacity for flexibility and responsiveness" (McArdle, 2010, p. 60).

Presumably, however, a knowledge base guaranteed through accreditation would serve as the ground for common identity and signify mastery within a said profession (Phelan, 2010). The educational market place requires an assurance that the student will meet the outcomes set by the degree program so that employment will follow. Underpinning this is the industry or professional body that interact with tertiary providers to ensure that graduates can meet industry professional requirements (such as standards). There is, therefore, a lot to think about when preparing students for their chosen profession and often quality teaching is misplaced in the process. The obvious path, therefore, leading to measurable student learning is quality teaching (Rowe, 2003). So how do we determine quality teaching?

Graduate attributes (GA) are jointly agreed upon outcomes that cross disciplines and provide a framework of measurable skills and competencies to ensure graduates can meet standards set by the university and make a positive contribution to their chosen profession. It is intended that the term graduate attribute 'include a broad range of personal and professional qualities and skills, together with the ability to understand and apply discipline based knowledge' (Thompson, Treleaven, Kamvounias, Beem \& Hill, 2008, p. 34). The following GA are an example: research and inquiry; ethical, social and professional understanding; communication; personal and intellectual autonomy and; information literacy. GA were established to acknowledge the responsibility tertiary institutions have 'to equip graduates with the attributes needed for lifelong learning in a rapidly changing world and workplace' (Thompson et al., 2008, p. 34). So how are these GA useful when integrated into curricula? Do they assure quality student learning occurs? If so, then how?

Evidence based practice supports the integration of GA into existing curricula (Barrie, 2007). Unfortunately, this integration is not consistent, as not all teachers in higher education understand GA and many do not know the rules and routines that surround curriculum modelling. Essentially, effective teaching at tertiary level requires the appropriate integration of GA into the curricula that support the professional standards (PS) with an obvious connection between assessment tasks (A) and learning outcomes (LO). This model gives an AOL and means students' experience a meaningful curriculum that promotes achievement of set outcomes measured through the assessments tasks. Unfortunately, the most commonly used indicator of achievement of learning is a grade received in an assessment task and often curricula is not aligned appropriately making the AOL difficult to validate. Attempts to ensure tertiary teachers integrate GA into their teaching have often met with resistance because the teachers lack an understanding of the process of curriculum modelling.

In a study cross faculty by Scanlon, et al., (2011), 'evidence' samples from each of the four disciplines of Teacher Education, Social Work, Economics/Business and Pharmacy were 
collected in the project to identify quality processes that assure learning and whether these might be applicable 'generically'. The project identified quality assurance processes in the four professional faculties that align curriculum outcomes with PS and GA. For example, there are seven key elements in the NSW Institute of Teachers graduate professional teacher standards to be demonstrated as achieved in the teacher preparation program (NSW Institute of Teachers, 2006, p. 2). In this example, these PS can be embedded into the curricula through the practice teaching report and individual course learning outcomes giving an AOL as a part of the tertiary teachers' reporting and accountability - just as their research activity, for example, can be measured through impact factors so can their students' learning experience.

\section{Curriculum modelling: essential for AOL}

In her recent article about improving student learning in higher education, McArdle, (2010) cites a 'roadmap" utilised by an education faculty to reform their curriculum for pre-service teachers. Under the careful direction of a program leader all stakeholders can understand that the alignment of individual courses' curricula contribute to the roadmap essential for a program to be effective. It is proposed that this roadmap starts with a mapping exercise for individual courses within a program so that all LO, teaching and learning activities (process) assessment tasks (product), GA and PS (if available) are aligned. The embedding of technology should occur during this mapping exercise either through the processes or products. Evidence should be collected by students to ensure the set LO are met and these LO should be represented in a grade descriptor or rubric in the assessment. All steps in the curriculum renewal will validate an AOL and should include continuous evaluation so that information can be processed and utilised to improve student learning. Students should be encouraged to contribute to the curriculum through continuous feedback and evaluation of the course they study.

There is evidence that assessment drives learning (Ramsden, 2003) and careful planning of the assessment processes can enhance student learning. This paper now describes an example a how to start curriculum modeling. Curriculum consists of all courses/courses/units of study within the whole certificate/diploma/degree program. Each individual course in the program has to be mapped and aligned before all courses in the program can be included in the curriculum model. The following exercise is an example of how the course LO are linked to the PS determined for beginning school teachers and supports how each standard is developed through the learning and teaching activities and the A in this one course - 'Introduction to Teaching'. Further, the GA can be aligned with the PS and LO. Curriculum modelling starts by creating a map where tabulating the essential components visually will assist in the process of alignment. It is imperative that the cycle of assessing students' needs is completed before planning the learning activities so the assessment task is designed to be achievable for the program 'stage' level of the student.

Collaboration with colleagues who are experienced in the curriculum modelling process is encouraged. Do not be too adventurous - think quality not quantity. Begin with clearly assigning the course LO. There are many different ways to set out a curriculum map and the following table shows how cross-referencing and alignment between the various components of the curriculum can be achieved. 
Table 1: Components of a curriculum map

\begin{tabular}{|l|l|l|l|l|}
\hline $\begin{array}{l}\text { Professional } \\
\text { Standard (PS) }\end{array}$ & $\begin{array}{l}\text { Learning } \\
\text { Outcomes } \\
\text { (LO) }\end{array}$ & $\begin{array}{l}\text { Learning \& } \\
\text { Teaching } \\
\text { activities } \\
\text { (L\&T) }\end{array}$ & $\begin{array}{l}\text { Assessment } \\
\text { tasks (A) }\end{array}$ & $\begin{array}{l}\text { Graduate } \\
\text { Attributes } \\
\text { (GA's) }\end{array}$ \\
\hline $\begin{array}{l}\text { Which PS is } \\
\text { being sought to } \\
\text { achieve? }\end{array}$ & $\begin{array}{l}\text { What is the LO } \\
\text { that supports } \\
\text { the } \\
\text { development of } \\
\text { this PS? }\end{array}$ & $\begin{array}{l}\text { How this PS is } \\
\text { developed } \\
\text { within the } \\
\text { course through } \\
\text { the L\&T? }\end{array}$ & $\begin{array}{l}\text { How this PS is } \\
\text { developed } \\
\text { within the } \\
\text { course through } \\
\text { the A? }\end{array}$ & $\begin{array}{l}\text { Which GA is } \\
\text { the focus? } \\
\text { HOWeasures the } \\
\text { L\&T? }\end{array}$ \\
\hline
\end{tabular}

The following table (Table 2) is an example of a partially completed map for one undergraduate course within the whole program - 'Introduction to Teaching', which is the first course in a teacher preparation program, Bachelor of Music (Music Education) degree.

Table 2: An example of a course (Introduction to Teaching) curriculum map

\begin{tabular}{|c|c|c|c|c|}
\hline $\begin{array}{l}\text { Professional } \\
\text { Standard (PS) }\end{array}$ & $\begin{array}{l}\text { Learning } \\
\text { Outcomes } \\
\text { (LO) }\end{array}$ & $\begin{array}{l}\text { Learning\& } \\
\text { Teaching } \\
\text { activities (L\&T) }\end{array}$ & $\begin{array}{l}\text { Assessment } \\
\text { tasks (A) }\end{array}$ & $\begin{array}{l}\text { Graduate } \\
\text { Attributes } \\
\text { (GA's) }\end{array}$ \\
\hline $\begin{array}{l}\text { Establish a } \\
\text { climate where } \\
\text { learning is } \\
\text { valued and } \\
\text { students' ideas } \\
\text { respected. } \\
\text { ELEMENT } \\
5.1 .3\end{array}$ & $\begin{array}{l}\text { Demonstrate } \\
\text { strategies to } \\
\text { create a } \\
\text { positive } \\
\text { environment } \\
\text { supporting } \\
\text { student } \\
\text { effort \& } \\
\text { learning. }\end{array}$ & $\begin{array}{l}\text { In our blog in the } \\
\text { ePortfolio, } \\
\text { outline the } \\
\text { relationships } \\
\text { between student } \\
\text { engagement and } \\
\text { student behaviour } \\
\text { and suggest } \\
\text { teaching trategies to } \\
\text { create a positive } \\
\text { learning } \\
\text { environment. }\end{array}$ & $\begin{array}{l}\text { Case study } \\
\text { analysis } \\
\text { involving an } \\
\text { observation of a } \\
\text { class (authentic } \\
\text { site visit or } \\
\text { DVD series } \\
\text { (e.g. Bill } \\
\text { Rogers). Write } \\
\text { in your } \\
\text { reflective } \\
\text { journal through } \\
\text { the ePortfolio. }\end{array}$ & $\begin{array}{l}\text { Lifelong } \\
\text { learning: } \\
\text { graduates } \\
\text { utilizing skills } \\
\text { of analysing, } \\
\text { interpreting } \\
\text { and teaching } \\
\text { music. }\end{array}$ \\
\hline
\end{tabular}

It can be seen through this example that the aligning of each component on the map ensures that quality teaching and learning is achieved through a strategic and structured process. The course mapping exercise allows for quality assurance in student learning and the systematic 
cross referencing invites colleagues and other interested parties (such as accreditation bodies) to view the process of learning and teaching in a transparent and methodical manner. Once the map has been decided upon all colleagues can collaborate and place all maps together to create a curriculum model for the entire program.

There is a strongly held belief that much of student learning takes place outside the lecture theatre and therefore, teaching is not that important. This is a myth and highlights the lack of understanding of what a curriculum really is. Student learning can be improved through appropriate planning and preparation of curricula. Through implementation and evaluation of the course the map can be modified in an attempt to achieve the optimal match of curriculum to students.

\section{4. eLearning can reinvigorate the student learning experience}

Quality graduates make a difference to society and industry benefits from well prepared early career professionals who bring innovation, creativity and a high standard of professional practices, beliefs and values to their job. The challenge is how to embed eLearning and, as discussed, this can be achieved through curriculum renewal and coordination of learning through specific pedagogic strategies. eLearning is replacing (modifying, enhancing?) traditional face-to-face $(\mathrm{F} 2 \mathrm{~F})$ teaching methods through blended learning - not only from a technology viewpoint but also through curriculum regeneration. eLearning is a set of pedagogical practices and the tertiary teacher must have a curriculum reason for this approach to learning and teaching. The promotion of new ways to communicate, engage with the course content and to measure and develop individual learners is essential ingredients for well rounded graduates (ODea \& Rowley, 2010).

The adoption of eLearning has broad implications including the preparing of students for operating in an environment of today's ever emerging technology revolution and this has implications inside and outside the higher education environment. So how to approach this within the context of ensuring a quality student learning experience at the tertiary level? There are many examples but this paper will focus on the emergence and adoption of the ePortfolio within tertiary teaching. This is not the first time portfolios have been used for gathering evidence of what a learner has accomplished. The ePortfolio, however, extends this traditional approach as the concept is really about students taking ownership for their own learning journey instead of being dictated to include mandatory components of the portfolio. The premise of the ePortfolio is that students engage in academic discourse as the portfolio model has been moved beyond assessment to empowering a students' learning landscape, as a key factor is student ownership. The ePortfolio encourages students to form judgements about their own learning, which contributes to their attainment of the set GA.

How do you embed the ePortfolio into curricula? The ePortfolio goes beyond the proving of knowledge and understanding of the information contained within a course. It allows students to analyse, synthesise and evaluate their learning in terms of their own learning journey. It also allows the students to map the learning journey themselves, as traditionally often the measure of attainment of the GA has been subjective. Finally, it allows for different approaches to documenting a students' profile as they incrementally build a learning autobiography over the course of the program (i.e. over 2, 3, 4 or more years).

As tertiary teachers we need to understand that the learner "stories" their experience (including the eLearning experience) rather than 'storing' these experiences and the ePortfolio allows evidence to be stored so that they can tell their story (Hughes, 2011). Examples of how the music education students at Unnamed University have responded to this story telling and how the ePortfolio has been embedded into the program through curriculum modelling follow. In understanding the role of ePortfolios in music students' tertiary program the students reported 
that they believed that the ePortfolio should be a representation of themselves in their professional practice role as both a musician and a music teacher:

"It's pretty much a documentation of us in our music career. What's happening in our music education course, where we provide evidence of us teaching, either in a school or privately" (Student 'Angie', 2012).

The students, at first, viewed it as a means of presenting themselves in a professional manner and they referred to it as a way of telling their story 'formally' in a Curriculum Vitae but also including a personal belief about teaching and learning:

"I think it can also say your beliefs of teaching and learning basically, or behaviour management and things like that. Not just your CV, your CV could be part of it, you can have where you've worked previously, what experiences you've had in different schools or that kind of thing, but also some of your beliefs about teaching" (Student 'Bev', 2012).

The student realizes she has a story to tell and is proud of this. The value noted here is in the repository - the ePortfolio has a wide range of possibilities for collection of evidence to support the story of students' learning journeys.

"I think the philosophy of why you want to become a teacher, I think is the main part out of everything. Why I want to be here. Why I want to do this. What's my aim? What's my purpose? I guess that's the main thing" (Student 'Angie', 2012).

Students mentioned that a philosophical statement of their beliefs about music education, therefore, should be placed in their ePortfolio. This example shows how the ePortfolio could impact assessment strategies in higher education, as it has the potential to include how students reflect on future professional practice.

\subsection{Reflective practice}

Rodman (2010) in her study sought to identify the ways that school teachers engage in reflection and how this engagement actually impacts on their teaching ability. She determined that pre service teachers who engaged in reflective practice were better able to manage learning outcomes and, as learners, they were better able to understand the impact of reflection on their practice (encouraging growth and improving pedagogical knowledge, teaching performance etc). The use of reflective practice by students and teachers in higher education, therefore, will depend on the course being studied and how the learning and teaching activities are designed (e.g. whether there is blended learning etc) and the assessment tasks.

The need for existing beliefs and knowledge of the students should be taken into account when designing curricula (Phillips, 2008). Personalising the learning to improve the students' experience includes teaching them how to reflect and engaging them in a professional dialogue about taking responsibility for their learning. The task for teachers is to decide how reflective practice can assist themselves as learners in student centered class. Schön (1987) states that the process of improved student learning depends greatly on a teachers' ability to reflect on their teaching practices and to improve their instruction through a response to this reflection. Treleaven and Voola (2008) support this by demonstrating that the graduate attributes are critical to the student being equipped to reflect on the content of their studies. For a tertiary teacher's professional development to enhance his/her teaching skills, the process of self-reflection as described by Schön (1987) should be included in a teacher's professional development programmes. For example, it is noted that the United Kingdom uses Schön's (1987) reflective practitioner theory in its teacher education programmes and it is reported that pre-service teachers are placed in an environment where they assist each other in solving 
classroom management issues as well as sharing of teaching skills and strategies (Baldwin, Vialle \& Clarke, 2000).

The development of reflective practice (such as a reflective learning journal) can complement and assist the students and teachers in understanding the world of the professional practitioner in a given discipline. This is where the reflection activities established through blended learning (for example, the ePortfolio) are valuable learning tools for both teacher and student.

As the capstone experience is 2, 3, 4 or more years in building a pathway to professional practice what is required is something that sorts the building blocks from the cement and the foreman from the labourer. Reflective practice can act as the conduit between all essential ingredients required by a student to demonstrate an achievement of the requirements for their tertiary program of study. An ePortfolio, therefore, has a "philosophy" embedded in it as the students are drawn to chart individual development and engage in the dialogues of both theory and practice. This is reflection -in -action and it brings the curriculum alive.

"The repeated use of reflection throughout their teacher preparation experience can be useful in encouraging growth and improving pedagogical knowledge, teaching performance and professional development among pre-service teachers" (Rodman, 2010, p. 20).

The use also of a blog (e.g. housed within the ePortfolio) also allows students to express personal growth along side their fears and anxieties about becoming a professional practitioner as it is designed as a 'space' free of ridicule (Hughes, 2011). The blog can not only be used for students " learning as the tertiary teacher will be able to co-learn with students (becoming a learner in the group of learners) which in turn creates another avenue for them to engage in professional development and model good pedagogical practices. By taking the threads of both students and teachers arguments and reflections learning can be truly collaborative as it is ongoing (Hughes, 2011). So consider the ePortfolio as a tool that will enhance learning and the reflection allowed through its processes as contributing to the enjoyment of learning (Rowley \& Dunbar-Hall, 2010).

\subsection{Creating professional practitioners}

New demands from government policy; institutional, industry (professional bodies) and generational change impact on teaching in higher education. Much of a tertiary institution's role in preparing their students for practice as professionals is measured through the success of their graduates to gain employment in quality industry and professional work places. Reputations of tertiary institutions, such as universities, are easily lost and hard fought to win as often the demands of the employer change rapidly with the evolving globalisation. Still, the tertiary institution must strive to prepare quality graduates and the quality of the student learning experience can be addressed through the exploration and understanding of effective teaching strategies, reflective practice and the careful planning of curricula (Rowley, 2006).

Barrie (2007) defends the need for graduate attributes because the tertiary sector must produce graduates who met industry designated accreditation. Many professional degree programs therefore have one or many professional bodies that determine the accreditation process. The learning outcomes that support the development of set professional standards by professional accreditation bodies, (such as the example previously discussed with the NSW Institute of Teachers for school teachers) promotes a sense of quality assurance that can be measured through the teaching and learning activities and the assessment tasks in that course. In this instance, accreditation has been designed to provide common reference points to describe and support the nature of teaching to school students in NSW. The benefit to the beginning professional's practice is that they have a framework for identifying and describing effective classroom teaching, and they have a clear picture of the connection between quality teaching 
and student learning. To continue with this example, for a beginning teacher to be accredited in NSW they must meet specific benchmarks in their first year of teaching and, if the teacher education course is not designed in line with the professional teacher standards, then the student is disadvantaged as a beginning teacher and the tertiary institution has not met requirements of the accrediting body in the development and delivery of their degree program. Professional teacher standards, therefore, can be identified and used in the design of teacher preparation curricula thus meeting accreditation requirements.

Ensuring competence and employability of the graduate is a focal point of most tertiary institutions and the process of informing tertiary teachers' practice to prepare students for professions is key in determining students' choice of program and institution.

\section{Conclusion: Improving the student learning experience}

Teaching in higher education is a dialogue between the teachers and students as it is collective, reflective, reciprocal, purposeful and supportive (Coffield, 2008). It should resemble a meeting of minds in academic discussion- not just be a participatory activity where students are talked at for an hour lecture. There is no simple solution to improving the student learning experience. The approach to teaching and learning described in this paper is informed by research that has demonstrated the importance of understanding the pedagogy to improve teaching in higher education. If accreditation, PS and GA have been designed to improve the quality of the graduate then there is a responsibility by teachers in higher education to improve the process required to produce quality early professional practitioners in their graduates. This process of aligning PS and GA with A and LO assures learning and promotes quality teaching in higher education as it has the potential to ensure that learning and teaching activities are selected by tertiary teachers with knowledge and understanding.

There is research to support that specific teaching methods, which are identified as good teaching practice in higher education, lead to improved student learning. More importantly, however, is the professional development of teachers and is essential to any professionals' practice. Guiding the reform of quality teaching is professional development that encourages tertiary teachers to use and model of good pedagogy. It is a key component for success in any teaching but particularly in tertiary education where the expert is under a spotlight of discipline specific knowledge and research.

"The main problem with preparing learners for the complexities of the world ahead is that higher education seems to take such a narrow view of what learning and knowledge are" (Jackson, 2010, p. xii).

Tertiary teachers who engage in the professional development of appropriate pedagogical practices also maintain a discreet understanding of the learner. One form of professional development is to understand the power of reflection and to engage in reflective practice. The use of ePortfolios is, therefore, recommended for use by the tertiary teacher as well as the teacher. Phillips (2008) makes a point about the need for practitioners to engage in professional development and universities should be providing this so that individuals can grow through their reflection on their practice and model good learning practices to engage students in their learning.

"Factors influencing the success of Professional Development activities include potential for workplace change, the diverse effect and understanding of adult learning principles, course specificity, effective mentoring and the relevance of the presented material (Phillips, 2008).

The intellectual challenge which teaching presents has been inadequately acknowledged or theorized in higher education. The principles of pedagogy described here in this paper are not new and quality teaching is always achievable. We, as tertiary teachers, must practice what we 
preach and be active and authentic models to the students. Ongoing professional development for tertiary teachers is part of the jigsaw puzzle solution, as it will impact what happens in the teaching environment. Well constructed curricula with alignment of the LO, PS, GA, and A is another part of the puzzle that will give the result of improved student learning.

\section{References}

Baldwin, A.Y.; Vialle, W. \& Clarke, C. (2000). 'Global professionalism and perceptions of teachers of the gifted'. In Heller, K.A.; Mönks, F.J.; Sternberg, R.J. \& Subotnik, R.F. (Eds.), International Handbook of Research and Development of Giftedness and Talent (3rd edition). Amsterdam: Elsevier. pp.565-572.

Barrie, S. C. (2007). A conceptual framework for the teaching and learning of generic graduate attributes. Studies in Higher Education, 32(4), 439-458.

Beetham, H. \& Sharpe, R. (2007) (Eds.) Rethinking Pedagogy for a Digital Age. Designing and delivering e-learning. London: Routledge

Coffield, F. (2008) Just suppose teaching and learning became the first priority... London: LSN

Dunbar-Hall, P. \& Rowley, J. (2010). ePortfolios for music educators: parameters, problems and possibilities. In W. Sims et al. (Eds), Proceedings of the 29th World Conference of the International Society for Music Education Conference, 2010 (p.61-64). Perth, Western Australia: ISME. Retrieved from http://issuu.com/official_isme/docs/isme29?viewMode=magazine\&mode=embed

Harvey, A. \& Kamvounias, P. (2008). Bridging the implementation gap: a teacher-as-learner approach to teaching and learning policy. Higher Education Research and Development. 27: $31-41$.

Hughes, J. (2011). Pebble PAD workshop. Held at Sydney eLearning on Friday February 18, 2011 as professional development for University of Sydney staff.

Jackson, N. (2010). 'Foreword'. In Nygaard, C.; Courtney, N. \& Holtham, C. (Eds.), Teaching creativity - Creativity in teaching. UK: Libri. pp.ix-xix.

Knowles, M. (1984). The Adult Learner: a neglected species (3rd ed). Houston: Gulf publishing.

McArdle, F. (2010). Preparing quality teachers: making learning visible. Australian Journal of Teacher Education 35 (8): 60-78.

NSW Institute of Teachers (2006). Professional Teaching Standards. Retrieved June 16,2007, from http://wwww.nswteachers.nsw.edu.au/main_Professsional_Teaching_Standards.html.

O'Dea, J. \& Rowley, J.L. (2010). A Quantitative Comparison of Change Over 12 months in Pre-service Music and PE Teachers Experiences and Perceptions of E-Learning and a Qualitative Analysis of Perceived Benefits and Enjoyment. 5th International Conference on e-Learning at the Universiti Sains Malaysia, Penang, Malaysia 12-13 July 2010. pp307-316. Retrieved from http://academic-conferences.org/icel/icel2010/icel10-home.htm

Phelan, A. (2010). Bound by recognition: some thoughts on professional designation for teachers. Asia Pacific Journal of Teacher Education, 38: 317-329.

Phillips, P. (2008). Professional development as a critical component of continuing teacher quality. Australian Journal of Teacher Education, 33 (1): 1-9. 
Ramsden, P. (2003). Learning to Teach in Higher Education (2nd Edition). London: Routledge-Falmer.

Rodman, G.J. (2010). Facilitating the teaching-learning process through the reflective engagement of pre-service teachers. Australian Journal of Teacher Education, 35 (2): 20-34.

Rowe, K. (2003). The importance of teacher quality as a key determinant of students' experiences and outcomes of schooling. Professional Learning and Leadership Development. NSW DET. Australia.

Rowley, J. (2006). What is quality teacher education for music education students? Proceedings of the 3rd International Conference on Teaching and Learning in Higher Education: TLHE Centre for Development of Teaching and Learning (CDTL), National University of Singapore, Singapore December 2006. pp228-230.

Rowley, J. \& Dunbar-Hall, P. (2010). Integrating e-portfolios for music teachers: a creative and pedagogic undertaking. In D. Gibson \& B. Dodge (Eds.), Proceedings of Society for Information Technology \& Teacher Education International Conference 2010 (pp. 213-215). Chesapeake, VA: AACE. Retrieved from http://www.editlib.org/p/33337.

Rowley, J.L., Dunbar-Hall, P. \& Bell, M. (2011, under review). More than a CV: Students and their reactions to electronic archiving of their studies in music education. Research Studies in Music Education (submitted)

Scanlon, L., Rowley, J.L., Laing, L., Treleaven, L., Smith, L. \& Taylor, J. (2011). Improving professional learning and teaching through the development of a quality process, which aligns curriculum objectives, outcomes and assessment with professional standards and graduate attributes. Interview notes recorded.

Schön, D.A. (1987). Educating the Reflective Practitioner. London: Jossey-Bass.

Thompson, D.; Treleaven, L.; Kamvounias, P.; Beem, B. \& Hill, E. (2008). Integrating graduate attributes with assessment criteria in business education using an online assessment system. Journal of University Teaching and Learning Practice. 5 (1), 34-48. Retrieved on January 10, 2011 from http://ro.uow.edu.au/jutlp/vol5/iss1/4

Treleaven, L., \& Voola, R. (2008). Integrating the Development of Graduate Attributes Through Constructive Alignment. Journal of Marketing Education, 30(2), 160-173.

Yancey, K.B. \& Weiser, I. (1997) (Eds.) Situating Portfolios. Four Perspectives. Utah: Utah State University Press. 